\title{
An Experimental Study of the Thermal State of a Steel Billet during Hot Rolling
}

\author{
Roman Dema ${ }^{1, *}$, Alexandr Koldin ${ }^{1}$, Vasily Banschicov ${ }^{1}$, Timur Murzabaev ${ }^{1}$, Ruslan \\ Amirov $^{1}$, and Elena Suvorova ${ }^{1}$ \\ ${ }^{1}$ Nosov Magnitogorsk State Technical University, 455000, Magnitogorsk, Lenin str., 38, Russia
}

\begin{abstract}
The technology of hot flat rolling is a complex technological process that includes multiple shaping of a steel billet,the temperature of a bullet ranging from 1100 to 900 degrees [1-6]. To deform a workpiece, mill rollsare used. The control over a workpiece thermal state is an important task aimed at the qualityof its manufacturing [7-13]. To achieve the goal, a mathematical model is developedfor calculating a steel billetthermal state. The modelmakes it possible to determinea temperature distribution along the whole length of a workpiece. The study results are useful for researchers and developers of the hot rolling technology,and they can be appliedinthe organization of the rolling process with an allowance for the temperature distribution. Based on the results, the parameters of steel billetproductioncan be adjusted or changed [14-18].
\end{abstract}

The aim of the study is the development of a mathematical model, describing a steel bullet thermal state during a hot rolling process.

\section{Implementation of the mathematical model for calculating a steel billet thermal state}

Mathematical modeling of a rolled strip thermal state is based on the numerical solution of the differential equation of thermal conductivity (a thermal conductivity equation).

Modeling of a rolled billet temperature field is based on solving a bidimensional problem of thermal conductivity (1). Acalculation model for solving the problem is shown in Figure 1.

$$
c \rho \frac{\partial T}{\partial \tau}=\lambda\left(\frac{\partial^{2} T}{\partial x^{2}}+\frac{\partial^{2} T}{\partial y^{2}}\right)
$$

Since the rolling speed of a billet is greater than the speedof heat spreading overa working roll $[19,20]$, the bidimensional modeling problem is simplified to a univariate one:

$$
c \rho \frac{\partial T}{\partial \tau}=\lambda\left(\frac{\partial^{2} T}{\partial y^{2}}\right)
$$

\footnotetext{
* Corresponding author: demarr78@mail.ru
} 
where the ratio $\frac{\lambda}{c \rho}=\alpha$ is temperature conductivity coefficient:

$\lambda$, coefficient of thermal conductivity of steel, $\mathrm{W} / \mathrm{m} \cdot{ }^{0} \mathrm{C} ; c$, specific heat capacity of steel, $\mathrm{J} / \mathrm{kg} \cdot{ }^{0} \mathrm{C} ; \rho$, density of steel, $\mathrm{kg} / \mathrm{M}^{3}$.

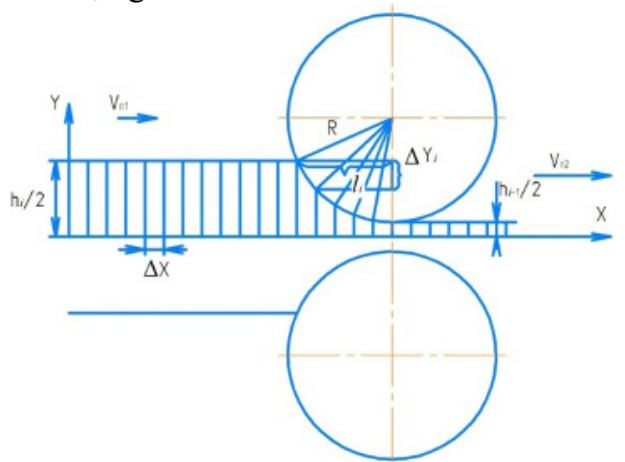

Fig. 1. A calculating scheme for modeling a rolled strip thermal state

Provided $v=\frac{\partial x}{\partial \tau}$ and $a=\frac{\lambda}{c \rho}$, we get

$$
v \frac{\partial T}{\partial x}=a \frac{\partial^{2} T}{\partial y^{2}}
$$

The work takes into account that in the process of deformation a rolled billet moves with an acceleration. Therefore, each step $\Delta x_{i}$ on the $\mathrm{x}$ coordinate is characterized by its own $\operatorname{speed} v_{i}$ which is found by the formula:

$$
\begin{gathered}
v_{i}=\frac{v_{i-1} h_{i-1}}{h_{i}} \\
\Delta y_{i}=\sqrt{R^{2}-\left(l_{i}-\Delta x\right)^{2}}-\sqrt{R^{2}-l_{i}^{2}} \\
l_{i}=\sqrt{R^{2}-\left(R-\frac{1}{2} h_{i}(1-\varepsilon)\right)^{2}}
\end{gathered}
$$

where $\mathrm{R}$, radius of the working rolls, $\mathrm{mm}$; l, length of the deformation zone arc, $\mathrm{mm}$. $\varepsilon$ is the drafting value, when rolling ani-strip in the $\mathrm{j}$-th stand, and it is determined by:

$$
\varepsilon_{(i ; j)}=\frac{h_{i-1}}{h_{i}}
$$

For each of the thermal zones of a rolled strip, we use the following equations:

- provided convective air cooling, which, depending on the character of the movement (laminar or turbulent), is determined according to the calculated value of Nusselt number [21-25]:

$$
\begin{gathered}
N u_{\text {liquid }}=0.33 X^{-0.5} \operatorname{Re}_{\text {liquid }}{ }^{0.5} \operatorname{Pr}_{\text {liqud }}^{0.33}\left(\frac{P r}{\text { Pr }_{\text {strip }}}\right)^{0.25} \\
R e_{c r}=\frac{v X_{c r}}{v}=5 \cdot 10^{5}
\end{gathered}
$$

- $\quad$ provided radiative heat transfer [21-25]:

$$
q_{(i)}=\varepsilon\left(T_{\text {strip }}\right) \sigma\left[(\text { Tstrip }+273)^{4}-(\text { Tair }+273)^{4}\right]
$$

where $\sigma$ is Stefan-Boltzmann constant; $T_{\text {air }}$ is an ambient (air) temperature. 
According to the works [21-25], the coefficient of radiative heat transferbetween the strip and the ambient (air) temperature (for steel) is determined:

- $\quad$ provided an increase in temperature due to a deformation of a strip [21-25]:

$$
\Delta T_{(i ; j)}=\frac{\sigma_{s(i)} \ln \varepsilon_{(i ; j)}}{\rho_{i} c_{i}}
$$

where $\sigma_{\mathrm{s}(\mathrm{i})}$, is a strain resistance of a rolled i-billet $\mathrm{MPa}$ [26];

- provided a heat transfer from the strip to the working roll (heat transfer in the system

"strip - roll" in j-th stand, according to [26]:

$$
q_{(i ; j)}^{s-\text { roll }}=\frac{\lambda\left(T_{\text {strip }}-T_{\text {roll }}\right)}{\sqrt{\pi a \tau}}
$$

where $\mathrm{T}_{\text {roll }}$ is a maximum working roll temperature, assumed in the center of a barrel, ${ }^{0} \mathrm{C}$.

\section{Numerical implementation of the mathematical model}

The mathematical model of a rolled strip thermal state is implemented in the form of a computer program, written in the Delphi 7.0 language. When executing the program, Rez.txt files are automatically created. They contain results of the program execution. The working window of the program is shown in Figure 2.

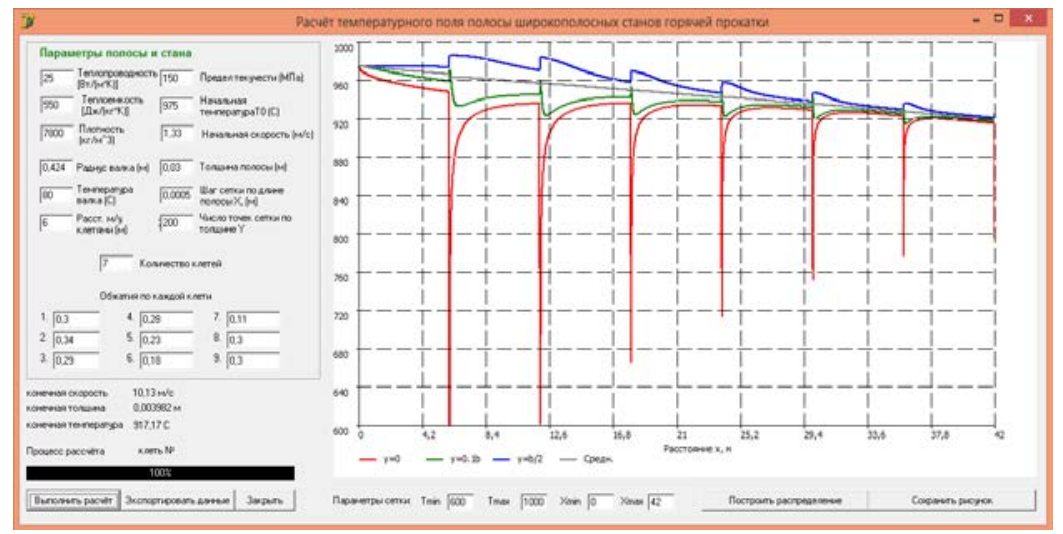

Fig. 2. A program window to implement the mathematical model of arolled strip thermal state

Parameters of a mill and a strip are necessary for the calculations. Mill parameters include: "a roll radius", " aroll temperature", "a distance between stands","a number of stands" (a maximum number of stands), "drafting for each j-th stand". Parameters of a strip include: thermophysical properties ("thermal conductivity", "heat capacity"), mechanical characteristics of a rolled strip ("yield strength", "density"), initial temperature, initial speed, thickness. The parameters: "Grid spacing along the x strip length" and "Number of pixelsin the y thickness" are the characteristics of the computational grid, their decrease improves the accuracy of mathematical calculations.

The computational result in the form of a diagram is displayed in the major window of the program (Figure 3).

The computational results allow constructing a diagram of temperature distribution along a strip when rolling in the direction of a sheet movement for the contact surface of a strip $(\mathrm{y}=0$ or $\mathrm{y}=\mathrm{h})$; and in the thickness of a strip: at $10 \%$ distance from the surface $(\mathrm{y}=$ $0.1 \mathrm{~h})$, at $25 \%$ distance from the surface $(\mathrm{y}=0.25 \mathrm{~h})$, at $50 \%$ distance from the surface $(\mathrm{y}=$ $0.50 \mathrm{~h})$, as well as the average value. 
The work provides with a theoretical study of temperature distribution alonga rolled strip. The material of a rolled billet is steelSt3kp. Figure 3 shows the results of the study.

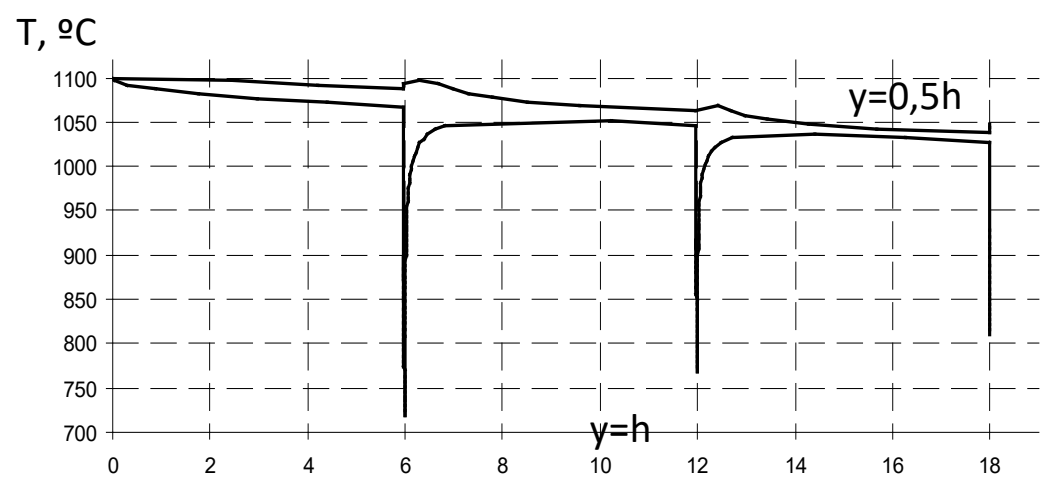

Fig. 3. The temperature distribution along a strip when rolling

Initial parameters: speed $2 \mathrm{~m} / \mathrm{s}$, thickness $12 \mathrm{~mm}$, temperature $1100 \mathrm{C}^{0}$, reduction $30 \%$. final parameters: speed $4,8 \mathrm{~m} / \mathrm{s}$, thickness $4,1 \mathrm{~mm}$, temperature $1037 \mathrm{C}^{0}$.

The analysis of the received data makes it possible to conclude that at the contact of a strip with working rolls there is a drop in temperature at a strip surface. It can be explained by the effect of the maximum heat takeoff (heat transfer) from a strip to the working surface of a tool. When passing subsequent stands (Fig.3) the drop in temperatureat the surface $(y=h)$ decreases. Itcanbeexplainedbyanincrease in speed of a rolled strip when drafting, when a contact time between a strip surface and working rolls decreases. In spite of the fact that a strip transfers some of its heat to working rolls, one can observe an increase in temperature (temperature perturbation)in deeper layers of a strip at the moment of plastic deformation. The heat,released at the moment of deformation, is evenly distributedthrough the volume, and it results in an average temperature increase(deformation perturbation) by $20 \ldots 50^{\circ} \mathrm{C}$. The received results correlate well with similar studies by the authors [21-25].

\section{Assessment of the reliability of the developed mathematical model of a rolled strip thermal state}

The study is carried out with the use of a thermal camera «SDS-Infrared HotFind-DXT» (the range of measurements is from $-20^{\circ} \mathrm{C}$ to $+1500^{\circ} \mathrm{C}$, the minimum distinguishable temperature difference is $0,10^{\circ} \mathrm{C}$ (at $30^{\circ} \mathrm{C}$ ), themeasurement accuracyis $\pm 2 \%$ ofthe readingvalues).

Measurements of temperature of stripsurfaces and working rolls are carried out in a certain sequence. Measuringa strip thermal state is carried out immediately before a billet's entering a stand. The results of the measurements are shown in Fig. 4. Measurements of the surface temperature of working rolls are taken at five points:directly in the process of rolling, after finishing the rolling and whenrolls being out of a stand. 

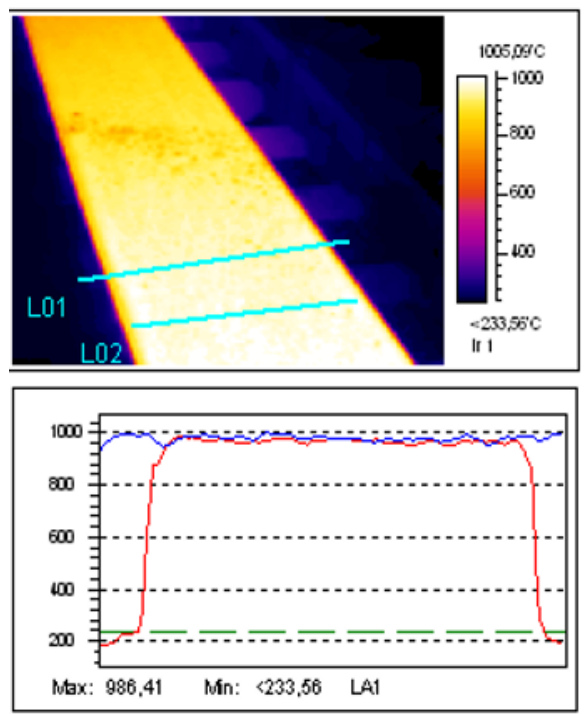

Fig. 4. An example of temperature measurement with the use of a thermal camera at mill "2000”PJSCMMK

Assessment of reliability of the developed mathematical model of a rolled strip thermal state is carried out by comparing the experimental and the computational data. Thecomparativeanalysis is conducted on two " 2500 " and "2000"sheet hot rolling mills of PJSC MMK. The analysis involves comparingsimulation results with control measurements used in production:

- when a strip leaves a roughing train:

$-\mathrm{T}_{3}\left({ }^{0} \mathrm{C}\right)$ for $2500 \mathrm{mil}$;

- $\mathrm{T}_{6}\left({ }^{0} \mathrm{C}\right)$ for 2000 mill;

- when a strip leaves finishing train;

$-\mathrm{T}_{11}\left({ }^{0} \mathrm{C}\right)$ for 2500 mill;

- $\mathrm{T}_{13}\left({ }^{0} \mathrm{C}\right)$ for 2000 mill.

The experimental temperature values are received from a shop data logging program. The analysis involves 300 hot rolling strips. Some of the results are shown in Table 1 .

Table 1. Comparison of computational results of the mathematical model of a rolled strip thermal state with experimental data

\begin{tabular}{|c|c|c|c|c|c|c|}
\hline \multirow{3}{*}{$\begin{array}{c}\text { Material of a } \\
\text { rolled } \\
\text { billet/thickness } \\
\text {, mm }\end{array}$} & \multicolumn{4}{|c|}{ Temperature values of a rolled billet } & \multirow{2}{*}{\multicolumn{2}{|c|}{ Discrepancy, \% }} \\
\hline & \multicolumn{2}{|c|}{ Roughing train } & \multicolumn{2}{|c|}{ Finishing train } & & \\
\hline & $\begin{array}{c}\text { measured } \\
\mathrm{T}_{3}{ }^{0} \mathrm{C}\end{array}$ & $\begin{array}{c}\text { computationa } \\
1 \\
\mathrm{~T}_{3}{ }^{0} \mathrm{C} \\
\end{array}$ & $\begin{array}{c}\text { measured } \\
\mathrm{T}_{11}{ }^{0} \mathrm{C}\end{array}$ & $\begin{array}{l}\text { computatio } \\
\text { nal } \\
\mathrm{T}_{11}{ }^{0} \mathrm{C}\end{array}$ & Roughing & Finishing \\
\hline $\begin{array}{l}\text { Boiling steel } \\
\text { 08, Calm } \\
\text { steel } 08 \\
\mathrm{~h}=2,0 \mathrm{~mm}\end{array}$ & 1080 & 1190 & 830 & 950 & $-10,19$ & $-14,46$ \\
\hline $\begin{array}{c}11 \text { кп, } 08 Ю \\
\mathrm{~h}=3,2 \mathrm{~mm}\end{array}$ & 1065 & 1172 & 862 & 989 & $-10,05$ & $-14,73$ \\
\hline $\begin{array}{l}\text { SAE1008 } \\
\mathrm{h}=1,8 \mathrm{~mm}\end{array}$ & 1085 & 1184 & 820 & 950 & $-9,12$ & $-15,85$ \\
\hline
\end{tabular}


The analysis of the received results (table 1) shows that the discrepancy range between experimental and theoretical datais $8 \ldots 21 \%$. It allows us to conclude that the developed mathematical model of a rolled strip thermal state is valid.

\section{Conclusions}

A mathematical model ofa rolled strip thermal state is developed and numerically implemented. It takes into account the influence of the following technological features of the hot sheet rolling process: heat exchange of a strip with rolls; volumetric heat generation during plastic deformation of a strip; change in the thermal state of a strip regarding the performanceof technological systems: hydraulic descaling, inter-stand cooling, as well as forced cooling of a strip before it enters a deformation zone.

This work is carried out within a framework of the government order (No. FZRU-2020-0011) of the Ministry of Science and Higher Education of the Russian Federation.

\section{References}

1. Matsuo A., Rolling Technology and Theory for the Last 100 Years: The Contribution of Theory to Innovation in Strip Rolling Technology, ISIJ International, 2015, Volume 55, Issue 1, 89-102.

2. Koldin, A.V. Modeling of the thermal state of the hot rolled strip in the accelerated cooling process part I: heat transfer model / A.V. Koldin, R.R. Dema, M.V. Nalimova, E. Mihailov, A.N. Shapovalov, M.V. Kharchenko // Journal of Chemical Technology and Metallurgy. - 2019. - T. 54. - № 6. - C. 1330-1336.

3. Koldin, A.V. Modeling of the thermal state of a hot rolled strip in an accelerated cooling process part 2: a calculation of the thermal field of the strip. results and conclusions / A.V. Koldin, R.R. Dema, M.V. Nalimova, A.N. Shapovalov, E. Mihailov // Journal of Chemical Technology and Metallurgy. - 2020. - T. 55. - № 1. C. 171-181.

4. NekitV., PlatovS., KrasnovM.The nature of the change of the surface temperature of the workpiece during hot rolling of pipe steel, MATEC Web of Conferences, 224(45):01104.

5. Tataru, A.S. Research and development of technology for the production of hot-rolled high-strength auto-sheet steel from two-phase ferrite-martensitic steels with specified mechanical properties: dis. ... Cand. tech. Sciences / A.S. Tataru; NUST MISIS. Magnitogorsk, 2018.

6. Shilyaev P.V., Denisov S.V., Stekanov P.A., Kornilov V.L., Krasnov M.L., Urtsev V.N., Kaptsan F.V., Shmakov A.V., Schastlivtsev V.M., Gornosturev Y.N., Lobanov M.L., Platov S.I. Production of new-generation rolled steel under conditions of magnitogorsk iron and steel company, Metallurgist.(безномера) 2021. 1-26.

7. Dema, R.R., Amirov, R.N., Latypov, O.R., Mathematical model for assessing the management of quality parameters of hot-rolled strips according to the criterion of local thickness variation, Materials Today: Proceedings, 2019, 19, стр. 2417-2421

8. Nekit V.A., Platov S.I., Kurbakov I.A., Golev A.D. Experimental Study of Lead and Lag in Rolling, Bulletin of the Magnitogorsk State Technical University. G.I. Nosov. 2015. No. 1 (49). S. 52-54. 
9. Kharchenko, M.V. Energy reduction technologies based on the lubricant supply in the roll contact system "quarto" during the hot strip rolling // M.V. Kharchenko, R.R. Dema, V.I. Bilichenko // Materials Science Forum. - 2016. Vol. 870. P. 446-453.

10. Dema, R.R. Dependents of energy consumption at the wide-strip hot rolling on a mode option of rolls lubrication modeling // R.R. Dema, O.B. Kalugina, N.Sh. Tyuteryakov // International Conference on Industrial Engineering, Applications and Manufacturing, ICIEAM 2017. - P. 8076435.

11. ShatalovR.L., MedvedevV.A. "Regulation of the Rolling Temperature of Blanks of Steel Vessels in a Rolling-Press Line for the Stabilization of Mechanical Properties," Metallurgist, vol. 63, no. 9-10, pp1071-1076, 2020

12. Trishevskii, O.I. and Saltavets, N.V., Mathematical model of the thermal state of strip in rolling, Steel Transl., 2009, vol. 39, no. 2, pp. 158-160.

13. BelskiyS.M.,YankovaS., ChuprovV.B., BakhaevK.V., StoyakinA.O., Temperature field of stripes under hot rolling, Journal of Chemical Technology and Metallurgy, 50, 6, 2015, 613-616

14. ChashchinV.V. Controlled Cooling of Strip Coils on the Conveyer of a Hot-Rolling Mill, Steel in Translation volume 48, pages388-392 (2018).

15. LiL.J., XieH.B., LiuX.,. LiuT.W, WangE.R., JiangZ.Y.Numerical Simulation of Strip Shape of High-Strength Steel during Hot Rolling Process, Key Engineering Materials (Volume 830)Pages:43-51 (2020)

16. KawallaR., GrechnikovF.V., NosovaE.A. and ErisovY.A. Development of a Mathematical Model of Plate Rolling on Hot Reversing Mills, Engineering Materials, Vol. 746, (2017), Pages: 48-55.

17. Kharchenko, M.V. Energy reduction technologies based on the lubricant supply in the roll contact system "quarto" during the hot strip rolling // M.V. Kharchenko, R.R. Dema, V.I. Bilichenko // Materials Science Forum. - 2016. Vol. 870. P. 446-453.

18. Dema, R.R. Dependents of energy consumption at the wide-strip hot rolling on a mode option of rolls lubrication modeling // R.R. Dema, O.B. Kalugina, N.Sh. Tyuteryakov // International Conference on Industrial Engineering, Applications and Manufacturing, ICIEAM 2017. - P. 8076435.

19. EfremovD.B., GerasimovaA.A., GorbatyukS.M, ChichenevN.A. "Study of kinematics of elastic-plastic deformation for hollow steel shapes used in energy absorption devices," CIS Iron and Steel Review, vol. 18, pp30-34, 2019

20. Tyuteryakov, N.S. Simulation and calculation of temperature distribution in roll fittings' guides in contact with the rolled strip // Procedia Engineering "2nd International Conference on Industrial Engineering, ICIE 2016" - 2016. - P. 667-673.

21. Sosedkova M.A., Grigorenko A.S., Radionova L.V. Mathematical model for calculating the temperature of the metal in a hot-sheet rolling mill, Bulletin of the Magnitogorsk State Technical University named after M.V. G.I. Nosov, Vol. 18 No. 4 2020, 24-31.[22] C. G. Sun, H. N. Han, J. K. Lee, Y. S. Jin, S. M. Hwang, A Finite Element Model for the Prediction of Thermal and Metallurgical Behavior of Strip on Run-out-table in Hot Rolling,ISIJ International, 2002 Vol. 42,No. 4, p. 392400 .

22. Ken-ichi YANAGI, Prediction of Strip Temperature for Hot Strip Mills, Transactions of the Iron and Steel Institute of Japan, 1976 Volume 16 Issue 1 11-19.

23. O.I. Trishevskii, N.V. Saltavets, Thermal state of strip in ultrafast cooling, Steel in Translation volume 45, pages443-446 (2015). 
24. A.Y. Albagachiev, A.M. Keropyan, A.A. Gerasimova, O.A. Kobelev, "Determination of rational friction temperature in lengthwise rolling," CIS Iron and Steel Review, 19, pp33-36, 2020

25. Latypov, O.R., Platov, S.I., Dema, R.R., Urtsev, N.V.Determination of the reduction coefficients in a continuous finishing group of stands in a hot rolling mill using artificial neural network, IOP Conference Series: Materials Science and Engineering, 2020, 966(1), 012101

26. Vorozhishchev, A.N., Dema, R.R., Kazakova, T.V.Modeling of a Thermal Massive Body Depending on the Cooling Liquid Volume, as Exemplified by Rolls for a Hotrolling Mill, Procedia Engineering, 2016, 150, стр. 1007-1012 